\title{
The Role of Imaging for MINOCA (Myocardial Infarction with No Obstructive Coronary Artery Disease): a Review of Literature and Current Perspectives
}

\author{
Mirvat Alasnag ${ }^{1} \cdot$ Qurat-ul-ain Jelani $^{2} \cdot$ Thomas W. Johnson $^{3} \cdot$ Biljana Parapid $^{4} \cdot$ Mohammed Balghaith $^{5}$. \\ Khaled Al-Shaibi ${ }^{1}$
}

Published online: 21 May 2020

(C) The Author(s) 2020

\begin{abstract}
Purpose of Review The objective of this review is to summarize scientific statements on the diagnosis and management of myocardial infarction with no obstructive coronary artery disease (MINOCA); define the diagnostic role of optical coherence tomography (OCT), intravascular ultrasound (IVUS), and cardiac magnetic resonance imaging (CMR); and provide representative case examples.

Recent Findings The majority of patients with MINOCA are evaluated by conventional coronary angiography. However, intracoronary imaging using OCT or IVUS permits more accurate understanding of the underlying pathology. These and other imaging modalities provide significant diagnostic and prognostic value.

Summary Although nonobstructive disease is the hallmark of the disease, MINOCA is associated with significant morbidity and mortality. Every effort to define the underlying pathology is necessary and requires more standardized use of imaging in clinical practice.
\end{abstract}

Keywords MINOCA · Imaging $\cdot$ IVUS $\cdot$ OCT

\section{Introduction}

The term MINOCA (myocardial infarction with no obstructive coronary artery disease) was coined to describe patients presenting with an acute myocardial infarction (AMI) without evidence of obstructive coronary artery disease (CAD) $[1,2]$. In the early studies of both ST elevation (STEMI) and non-ST

This article is part of the Topical Collection on Intravascular Imaging

Mirvat Alasnag

mirvat@jeddacath.com

1 Cardiac Center, King Fahd Armed Forces Hospital, PO Box 9862, Jeddah 21159, Saudi Arabia

2 Section of Cardiology, Department of Internal Medicine, Yale School of Medicine, New Haven, CT 06510, USA

3 Bristol Heart Institute, University Hospitals Bristol NHS Foundation Trust, Upper Maudlin St., Bristol BS2 8HW, UK

4 Belgrade University School of Medicine, Belgrade, Serbia

5 King Abdulaziz Cardiac Center, King Saud bin Abdulaziz University for Health Sciences, Riyadh, Saudi Arabia elevation myocardial infarction (NSTEMI), approximately $10 \%$ of patients had no significant CAD on coronary angiography, a finding that was later confirmed in several AMI registries [3-6]. Epidemiologically, MINOCA is a syndrome with a prevalence of 6-14\%. Several etiologies have been recognized including, but not limited to, plaque disruption, coronary spasm, and coronary thromboembolism [7]. Further evaluation is necessary to determine the underlying diagnosis, appropriate management, and prognosis of individuals with MINOCA.

\section{Clinical Presentation and Outcomes}

Clinically, patients with MINOCA may be differentiated from patients with a myocardial infarction (MI) secondary to atherosclerosis by certain characteristics. Several large registries reported MINOCA in predominantly young female patients (up to 40\%) presenting with NSTEMI [7-9]. MINOCA patients are unique in that they have a lower prevalence of traditional atherosclerotic cardiovascular risk factors and have a lower but clinically significant annual mortality rate [5, 7]. Safdar et al. reported a 54\% prevalence rate for dyslipidemia 
and hypertension in those with MINOCA in the Variations in Recovery: Role of Gender on Outcomes of Young AMI Patients (VIRGO) study [10]. The VIRGO study also revealed that patients with MINOCA had a higher prevalence of hypercoagulable disorders and were more likely to be non-white [10]. This study demonstrated that the course of MINOCA was not benign. The length of hospital stay and short- and long-term outcomes in MINOCA were similar to patients with $\mathrm{MI}$ and CAD (MICAD). However, the 12-month mortality for MINOCA was two times higher than the $0.5 \%$ annual mortality rate observed for middle-aged women in the general population of the USA [11]. In the SWEDEHEART registry, approximately $6 \%$ of patients with MINOCA had a subsequent MI, with progression of clinically important coronary artery stenosis at the time of the second MI [12]. In this registry, $22 \%$ of patients with MINOCA who had developed a reinfarction died during the follow-up period.

In the VIRGO registry, MINOCA phenotypes were classified into 5 types: class I included patients with atherosclerotic obstructive disease who underwent revascularization; class II included those with obstructive coronary artery disease $(\geq$ $50 \%$ ) without evident plaque rupture/thrombosis; class III included nonobstructive coronary artery disease $(<50 \%)$; class IV included patients with a non-plaque mechanism such as coronary artery vasospasm (relieved by intracoronary nitroglycerin), spontaneous coronary artery dissection (SCAD), and coronary embolization; and class $\mathrm{V}$ included those with an unidentified pathology. Intracoronary imaging was not utilized for classification [4]. A comprehensive list of possible underlying etiologies is described in Table 1. The most

Table 1 Underlying pathophysiological mechanisms/possible etiologies of MINOCA

\begin{tabular}{lll}
\hline Coronary causes & $\begin{array}{c}\text { Non-coronary } \\
\text { cardiac causes }\end{array}$ & $\begin{array}{l}\text { Non-cardiac } \\
\text { disorders }\end{array}$ \\
\hline $\begin{array}{l}\text { Vasospastic angina } \\
\begin{array}{l}\text { Coronary microvascular } \\
\text { disorders }\end{array}\end{array}$ & $\begin{array}{c}\text { Takotsubo } \\
\text { cardiomyopathy }\end{array}$ & $\begin{array}{c}\text { Pulmonary } \\
\text { embolism } \\
\text { Renal impairment }\end{array}$ \\
$\begin{array}{l}\text { 1. Microvascular angina } \\
\begin{array}{l}\text { 2. Microvascular spasm } \\
\text { 3. Coronary slow flow }\end{array}\end{array}$ & \\
$\begin{array}{l}\text { Coronary plaque disruption } \\
\text { Other } \\
\text { cardiomyopa- } \\
\text { thies }\end{array}$ & $\begin{array}{c}\text { Stroke } \\
\text { Spontaneous coronary } \\
\text { Thrombosis/embolism }\end{array}$ \\
$\begin{array}{l}\text { Coronary artery dissection } \\
\text { Acute aortic dissection } \\
\text { extending } \\
\text { into the coronary arteries }\end{array}$ & & $\begin{array}{c}\text { Sepsis } \\
\text { Acute respiratory } \\
\text { distress } \\
\text { syndrome }\end{array}$ \\
\hline
\end{tabular}

common causes include plaque disruption, coronary artery spasm, thromboembolism, coronary dissection, Takotsubo cardiomyopathy, myocarditis, and other forms of type 2 myocardial infarction $[13,14]$. The CRUSADE by Patel et al evaluated the prevalence, predictors and outcomes of NSTEMI with insignificant coronary disease. The investigators reported an incidence of MINOCA of $9 \%$ with a low incidence of adverse outcomes. The strongest predictors of insignificant obstructive coronary artery disease were female sex and young age. Propensity-Matched analysis From the Acute Catheterization and Urgent Intervention Triage Strategy Trial (Acuity) noted that individuals with a NSTEMI and elevated troponin levels without obstructive coronary disease have a low rate of subsequent myocardial infarction and unplanned revascularization. However, they are at risk for 1-year mortality from non-cardiac causes $[15,16]$.

\section{Position Statements for the Diagnosis and Management of MINOCA}

In order to address the varying pathophysiologies, etiologies, disease characteristics, and outcomes associated with

Table 2 Diagnostic criteria for myocardial infarction with nonobstructive coronary arteries (MINOCA)

The diagnosis of MINOCA is made after coronary angiography in a patient presenting with an acute myocardial infarct based on the following criteria

\section{AMI criteria}

(a) Positive cardiac biomarker (preferably cardiac troponin) defined as a rise and/or fall in serial levels, with at least one value above the 99th percentile upper reference limit

(b) Corroborative clinical evidence of infarction including at least one of the following:

(i) Symptoms of ischemia

(ii) New or presumed new significant ST-T changes or new LBBB

(iii) Development of pathological Q waves

(iv) Imaging evidence of new loss of viable myocardium or new RWMA

(v) Intracoronary thrombus evident on angiography or at autopsy

2. Nonobstructive coronary arteries on angiography

(a) Defined as the absence of obstructive CAD on angiography (no coronary artery stenosis $\geq 50 \%$ ) in the infarct-related artery

(b) This includes patients with the following:

(i) Normal coronary arteries (no stenosis $>30 \%$ )

(ii) Mild coronary atherosclerosis (stenosis $>30 \%$ but $<50 \%$ )

3. No clinically overt specific cause for the acute presentation

(a) At the time of angiography, the specific diagnosis is not apparent

(b) It is necessary to further evaluate the patient for the underlying cause of MINOCA

$\angle B B B$ left bundle branch block, $R W M A$ regional wall motion abnormalities, $C A D$ coronary artery disease 
MINOCA, position statements were developed by the European Society of Cardiology (ESC) in 2017 and the American Heart Association (AHA) in 2019. These statements described the diagnostic criteria for MINOCA based on both clinical and imaging criteria (Table 2) [2]. The Fourth Universal Definition of MI is employed in addition to the coronary angiographic finding of no coronary artery stenosis $\geq 50 \%$ in the infarct-related artery. In the diagnosis of MINOCA, it is important to exclude alternate causes for an elevated troponin such as sepsis or pulmonary embolism. It is equally important to rule out obstructive disease that may have gone unrecognized by the basic angiogram such as subtle plaque disruption or embolism as well as microvascular dysfunction and vasospasm. Finally, diseases that can mimic an MI (e.g., myocarditis) must also be appropriately diagnosed. An algorithm to evaluate the myocardium with cardiac magnetic resonance (CMR) imaging, intracoronary structure with intravascular ultrasound (IVUS), and optical coherence tomography (OCT) as well as provocative testing for spasm and vasomotor integrity is endorsed by the ESC and AHA position statements (Fig. 1). In other studies, inducible coronary artery spasm has been reported in $27 \%$ and thrombophilia disorders in $14 \%$ of patients.

\section{Cardiac Magnetic Resonance Imaging}

As mentioned earlier, the diagnosis of MINOCA may trigger multiple different diagnostic evaluations depending on the clinical presentation. For the initial work-up, echocardiography and left ventriculography may provide information about the ejection fraction and wall motion abnormalities. In studies targeting potential etiologies of MINOCA, cardiac magnetic resonance (CMR) imaging has been a useful preliminary investigation and has been cited as the key diagnostic tool $[2$, 17]. Late gadolinium enhancement (LGE) is useful not only in the localization of the area of myocardial damage, but it can provide insights into the mechanism. For example, subendocardial LGE suggests an ischemic cause of injury, while a non-ischemic pattern may suggest myocarditis or an infiltrative disorder. CMR may also show large areas of myocardial edema with/without necrosis among MINOCA patients with plaque disruption, suggesting temporary cessation of flow [17-19]. Some CMR-based studies have shown typical MI in about $24 \%$ of patients, myocarditis in $33 \%$, and no significant abnormalities in 26\%. CMR can determine the extent of myocardial damage, left ventricular volumes, and function, thereby providing objective data to guide treatment and

\section{MINOCA}

\section{Universal definition of AMI +}

\section{Absent coronary stenosis $\geq 50 \%$}

Invasive Testing:

1. Intracoronary nitrates (Spasm)

2. LV Gram/Echo (Takotsubo)

3. IVUS/OCT (Plaque disruption)

4. Pressure wire (Microvascular dysfunction)

5. Provocative spasm testing (not during AMI)

\section{MINOCA Confirmed:}

-Type-2 MI

-Plaque Disruption

-Takotsubo

-Epicardial spasm or microvascular dysfunction

-Coronary Thromboembolism

Fig. 1 Diagnostic algorithm for MINOCA. LV Gram, left ventriculogram; echo, echocardiogram; Hb, hemoglobin; CRP, Creactive protein; $\mathrm{SO}$, oxygen saturation; $\mathrm{BNP}$, brain natriuretic
Laboratory Testing:

1. Type-2 MI (Hb, CRP, SO2)

2. D-Dimer (Pulmonary embolism)

3. Thrombophilia screeing

4. BNP

\section{MINOCA NOT Confirmed:}

-Cardiac MRI (LGE for myocarditis vs AMI)

-TEE (Cardiac source of embolization eg Left atrial

appendage thrombus)

peptide; LGE, late gadolinium enhancement; AMI, acute myocardial infarction; TEE, transesophageal echocardiogram 
prognosis. In their recent publication, Dastidar et al. reported that CMR identified the cause for the troponin rise in $74 \%$ of patients (25\% myocarditis, $25 \%$ MI, and $25 \%$ cardiomyopathy). A normal CMR was reported in $26 \%$. Over a median follow-up of 3.5 years, $5.7 \%$ patients died. Patients with cardiomyopathy had the worst prognosis ( $15 \%$ mortality), followed by MI (4\% mortality) and myocarditis ( $2 \%$ mortality). The investigators concluded that a CMR diagnosis of cardiomyopathy and ST segment elevation are the most important predictors of mortality [17]. Examples highlighting the utility of CMR in diagnosing myocarditis and myocardial injury with corresponding normal coronary arteries are provided in Figs. 2, 3.

\section{Intracoronary Imaging}

The angiographic cut-off of $<50 \%$ stenosis for a diagnosis of MINOCA is limited by substantial inter- and intra-observer variability in visual estimation of stenosis. Similarly, the infrequent use of intravascular imaging often results in missed diagnoses of substantial atherosclerosis or thrombosis/spasm in suspected MINOCA cases. At the time of cardiac catheterization, intracoronary imaging, either with IVUS or OCT, is valuable in identifying plaque disruption as well as coronary dissection or thrombosis [2]. Plaque disruption is a frequent cause of MINOCA and accounts for 5-20\% of all type 1 AMI cases. In two studies using IVUS, plaque disruption was found in approximately $40 \%$ of patients with MINOCA [20,21]. The use of IVUS and OCT is still limited in spite of the well-recognized limitations of conventional coronary angiography alone. Both these modalities can guide and optimize most percutaneous revascularization procedures, as they can characterize the underlying plaque with identification of calcium burden, identify suboptimal stent apposition and expansion, define the mechanisms of stent failure (stent restenosis and stent thrombosis), and have been found to potentially lower contrast volume in dedicated low-contrast IVUS laboratories, commonly referred to as zero-contrast or low-contrast studies [22]. However, the ULTIMATE IVUS trial demonstrated greater contrast use with IVUS-guided strategy compared with an angiogram-only treatment strategy. While considered a relatively newer technique when compared with IVUS, OCT offers higher resolution and more anatomic detail [23]. For example, the CLI-OPCI II Study not only identified specific features of suboptimal stent expansion by OCT, but it also demonstrated higher adverse clinical outcomes in those with suboptimal stenting [24]. In contrast to IVUS, OCT uses infrared light for imaging. OCT catheters deliver and collect near infrared light with a wavelength of approximately 1300 $\mathrm{nm}$ to create cross-sectional images of the artery lumen and wall [25]. The infrared OCT machine measures echo time delay and signal intensity of the reflected or back-scattered
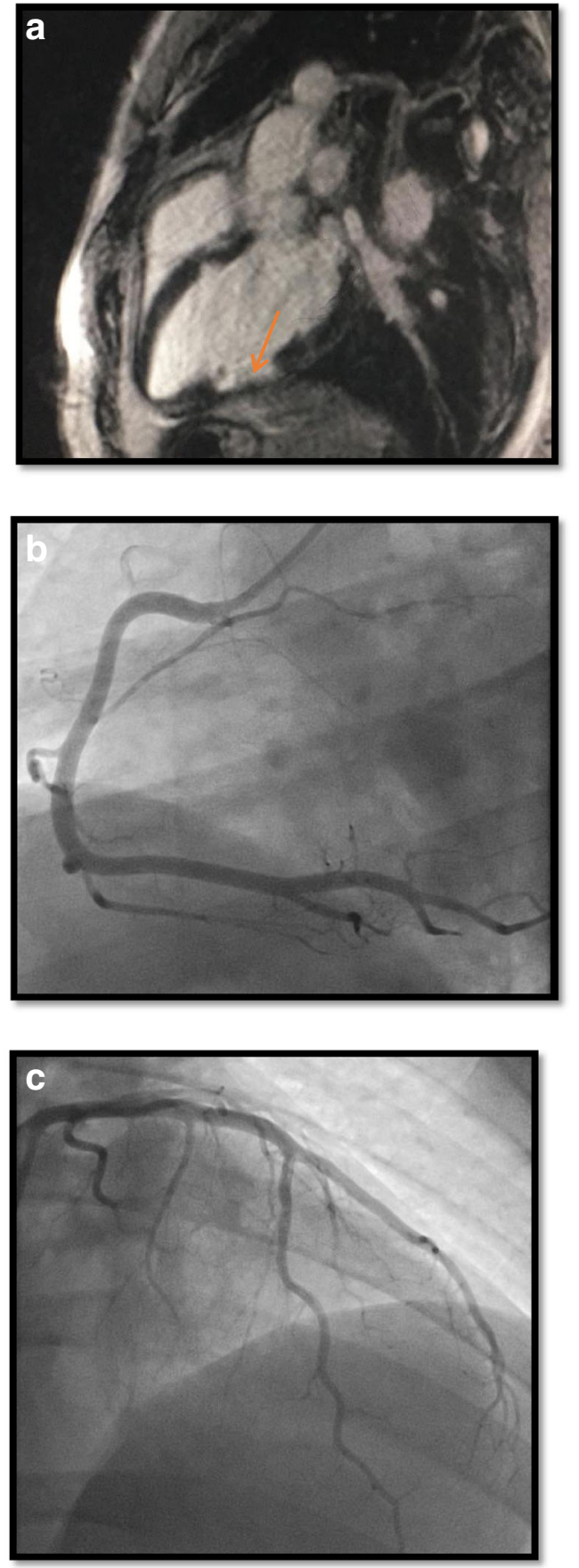

Fig. 2 a CMR image of MINOCA with a normal coronary angiogram. A 27-year-old gentleman with a 10-year history of smoking was admitted with atypical chest pain, dynamic EKG changes, and serum high sensitivity troponin that was elevated up to $8 \mathrm{ng} / \mathrm{l}$. Transthoracic echocardiography shows infero-basal hypokinesia with an ejection fraction of $50 \%$. The cardiac magnetic resonance (CMR) study demonstrated focal transmural edema of the inferolateral wall with corresponding focal transmural late gadolinium enhancement (LGE). b Coronary angiogram of the normal right coronary artery (left anterior oblique view). c Coronary angiogram of the normal left anterior descending coronary artery (right anterior oblique, cranial view)

light from the coronary wall structures during a pull-back along the coronary artery [26]. Cross sections of the coronary 

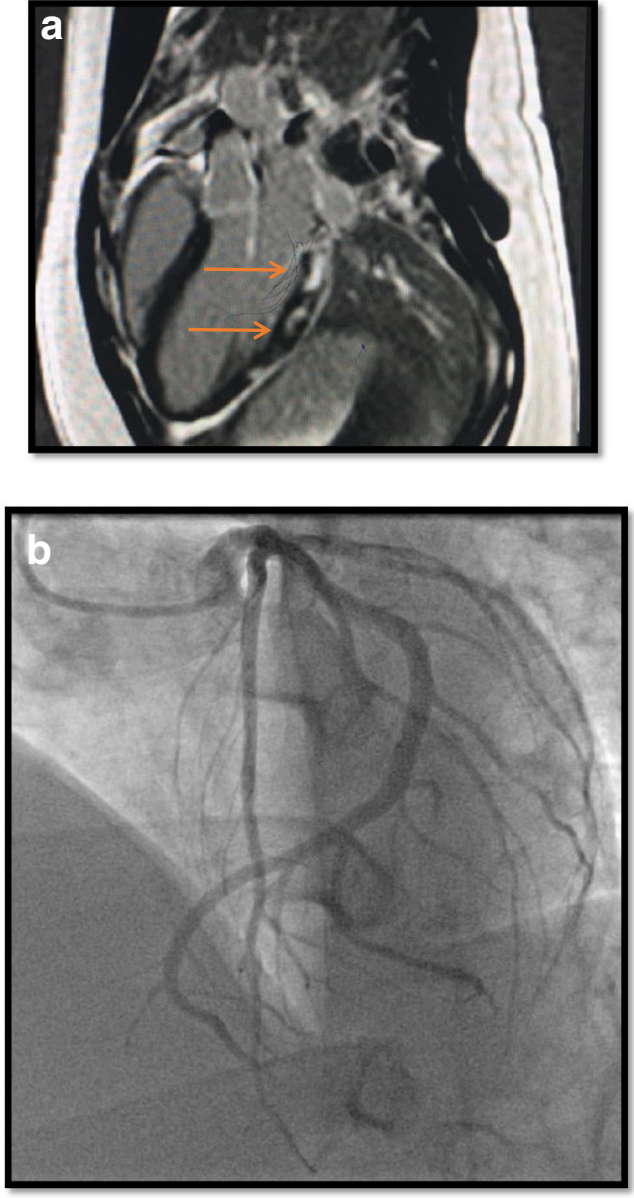

Fig. 3 a CMR image of myocarditis. A 19-year-old gentleman whose cardiovascular risk factors include smoking and hyperlipidemia was admitted through the ER with a NSTEMI. An echo revealed a preserved LV function with EF 50\%. CMR demonstrated diffuse edema with patchy epicardial and midwall LGE. b Coronary angiogram of the normal left anterior descending and dominant left circumflex coronary artery (left anterior oblique, cranial view)

artery are then created allowing for real and offline analysis of each section. Axial resolution with OCT $(100-200 \mu \mathrm{m})$ is much higher than that of IVUS (10-20). Another important difference is the lower depth of tissue penetration with OCT (2-3 mm) compared with IVUS (4-8 $\mathrm{mm})$ [25]. Table 3 provides an overview of key differences between OCT and IVUS.

There are numerous advantages to adopting intracoronary imaging, OCT in particular, to complement coronary angiography; OCT can (1) differentiate tissue characteristics including plaque components (fibrous, calcified, versus lipid-rich plaque) [26]; (2) identify unstable plaque [27]; (3) differentiate plaque rupture vs erosion [28]; (4) identify red and white thombi [29]; (5) identify spontaneous or edge dissection during $\mathrm{PCI}^{-}$[30]; and (6) detect incomplete stent apposition as well as in-stent restenosis [31-33]. Given the wide applications of intracoronary imaging, it can be useful in patients with
Table 3 Major differences between OCT and IVUS including technical and pathological characterization of coronary lesions

\begin{tabular}{lll}
\hline & OCT & IVUS \\
\hline Tissue penetration & $1-2 \mathrm{~mm}$ & $6-10 \mathrm{~mm}$ \\
Technology & Near infrared & Ultrasound \\
Pull-back speed & $20 \mathrm{~mm} / \mathrm{s}$ & $1 \mathrm{~mm} / \mathrm{s}$ \\
Resolution & & \\
Axial & $10-20 \mu \mathrm{m}$ & $100-200 \mu \mathrm{m}$ \\
Transverse & $20-40 \mu \mathrm{m}$ & $200-300 \mu \mathrm{m}$ \\
Minimum guide catheter size & $5 \mathrm{Fr}(6 \mathrm{Fr}$ preferable $)$ & 5 French \\
Maximum frame rate & $100 \mathrm{frames} / \mathrm{s}$ & 30 frames/s \\
Lines per frame & 500 & 256 \\
Blood removal with contrast & Yes & No \\
Pathological characterization & & \\
Necrotic core & ++ & + \\
Thin-cap fibroatheroma & +++ & - \\
Thrombus & +++ & + \\
Stent apposition/expansion & +++ & ++ \\
Dissection & +++ & ++ \\
Calcium & ++ & +++ \\
Ostial lesion evaluation & + & ++ \\
\hline
\end{tabular}

OCT optical coherence tomography, IVUS intravascular ultrasound, $\mathrm{mm}$ millimeter, $\mu m$ micrometer, $\mathrm{Fr}$ French

+++: excellent assessment

++ : good assessment

+ : average assessment

-: poor assessment

MINOCA as it may identify the pathophysiological process and etiology. The second consensus document of the European Association of Percutaneous Cardiovascular Interventions (EAPCI) on the clinical use of intracoronary imaging focused on the utility of IVUS, OCT, and NIRS in facilitating angiographic interpretation and guidance of treatment of acute coronary syndromes beyond the mere guidance of stent selection and optimization of deployment [34]. In a study of 38 patients presenting with MI, plaque disruption was identified in $40 \%$ of patients with MINOCA [35]. Similarly, coronary thrombus was identified in 7 patients. In patients presenting with spontaneous coronary artery dissection (SCAD) [36], OCT was used to describe the presence and absence of fenestrations between the true (TL) and false lumens (FL). The authors found that in the absence of fenestrations, there was a significantly larger expansion of external elastic lamina and a larger false lumen; there were no significant differences in the density of the vasa vasorum in SCAD compared with the control subjects. Figure 4 is a representative panel of patients presenting with MINOCA and their corresponding $\mathrm{OCT}$ images. 
Fig. 4 OCT Panels of patients with MINOCA. Panel 1: A 52-

year-old female presents with 2-h history of chest pain and inferior ST elevation on ECG. Risk

factors include smoking and a family history of ischemic heart disease. Angiography demonstrates a moderate proximal stenosis with an intraluminal filling defect likely representing thrombus (level A/A'). Immediate intracoronary imaging with OCT (panel A) reveals an irregular lumen contour and deep structure attenuation with minimal intimal thickening from 7 to 1 o'clock. Repeat OCT analysis 5 weeks later demonstrates resolution of the irregular lumen contour with evidence of an underlying thickcap fibroatheroma (panel A'). Panel 2: A 48-year-old female presents with 24-h history of chest pain and T-wave inversion in ECG leads V2-V6. Her troponin is elevated, her cardiovascular risk factors are limited to smoking, and a family history and angiography is undertaken within $24 \mathrm{~h}$ on admission. A moderate stenosis is observed in the midLAD segment. OCT assessment reveals significant luminal restriction with evidence of dehiscence of the intimo-medial complex from the adventia (panel B), despite normal vessel architecture in the distal vessel (panel C), indicative of a type III spontaneous coronary artery dissection (a lesion mimicking coronary atherosclerosis). Panel 3: A 45-year-old intravenous drug user with a previous history of a conservatively managed myocardial infarction presented with chest pain and transient anterior T-wave changes.

Angiography demonstrated a non-flow limiting abnormality in the mid-LAD with linear defects consistent with possible coronary dissection. OCT assessment demonstrated multiple lumens with fibrotic septae suggestive of a recanalized thrombus (panel D)
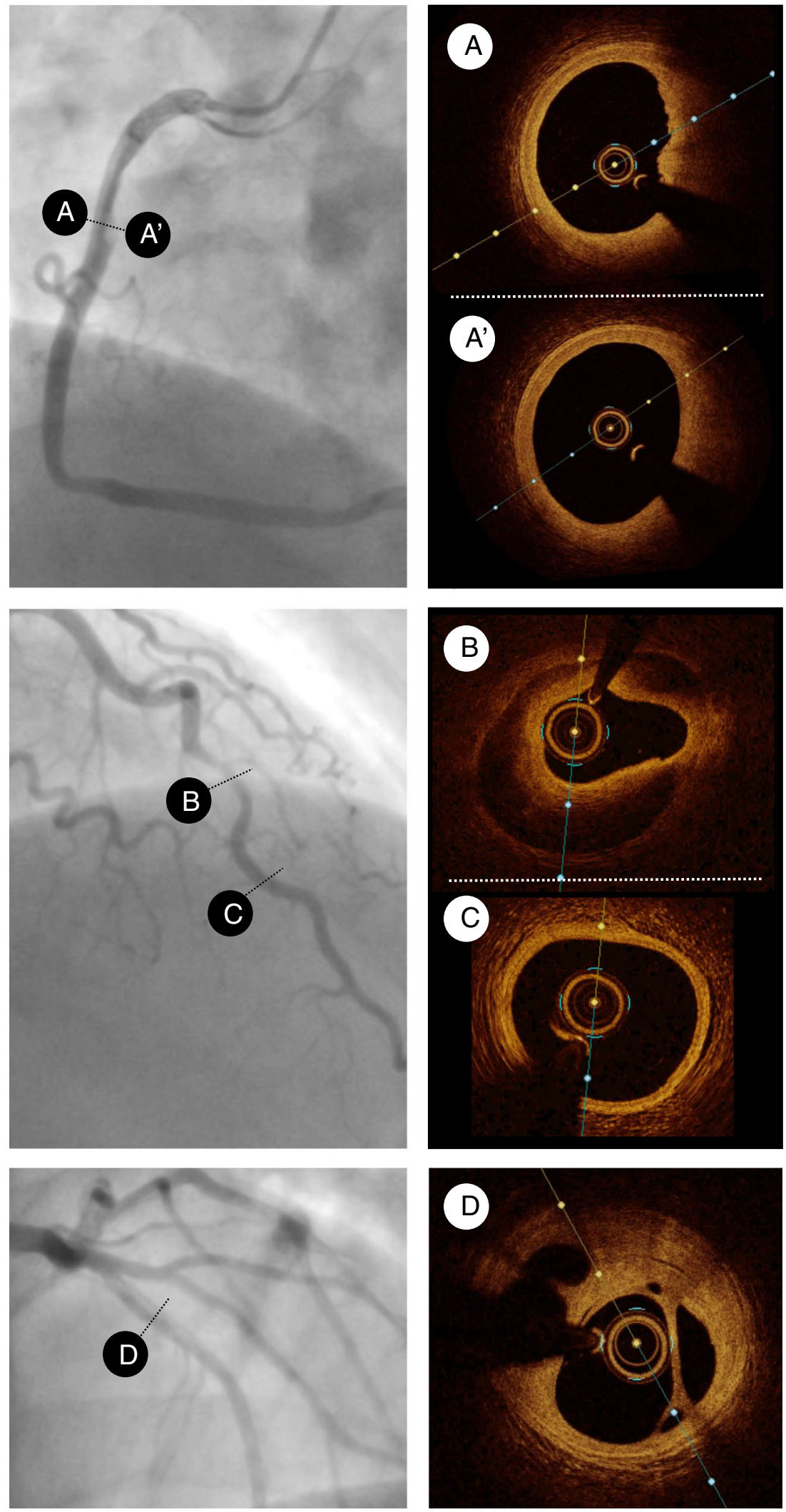


\section{Conclusion}

Conventional coronary angiography has been the standard method of investigation for individuals presenting with an MI whether MINOCA or MICAD. However, with advancements in both intracoronary imaging and noninvasive cardiac imaging technologies, especially CMR, a more accurate diagnosis of the underlying pathology may be achieved. Such modalities not only add diagnostic value, but they are useful in tailoring management and prognosticating long-term outcomes in MINOCA patients.

\section{Compliance with Ethical Standards}

\section{Conflict of Interest All authors declare no conflict of interest.}

Human and Animal Rights This article does not contain any studies with human or animal subjects performed by any of the authors.

Open Access This article is licensed under a Creative Commons Attribution 4.0 International License, which permits use, sharing, adaptation, distribution and reproduction in any medium or format, as long as you give appropriate credit to the original author(s) and the source, provide a link to the Creative Commons licence, and indicate if changes were made. The images or other third party material in this article are included in the article's Creative Commons licence, unless indicated otherwise in a credit line to the material. If material is not included in the article's Creative Commons licence and your intended use is not permitted by statutory regulation or exceeds the permitted use, you will need to obtain permission directly from the copyright holder. To view a copy of this licence, visit http://creativecommons.org/licenses/by/4.0/.

\section{References}

1. Beltrame JF. Assessing patients with myocardial infarction and nonobstructed coronary arteries (MINOCA). J Intern Med. 2013;273:182-5.

2. Agewall S, Beltrame JF, Reynolds HR, Niessner A, Rosano G, Caforio AL, et al. ESC working group position paper on myocardial infarction with non-obstructive coronary arteries. Eur Heart J. 2017:38:143-53.

3. DeWood MA, Spores J, Notske R, Mouser LT, Burroughs R, Golden MS, et al. Prevalence of total coronary occlusion during the early hours of transmural myocardial infarction. N Engl J Med. 1980;303:897-902.

4. DeWood MA, Stifter WF, Simpson CS, Spores J, Eugster GS, Judge TP, et al. Coronary arteriographic findings soon after nonQ-wave myocardial infarction. N Engl J Med. 1986;315:417-23.

5. Gehrie ER, Reynolds HR, Chen AY, Neelon BH, Roe MT, Gibler WB, et al. Characterization and outcomes of women and men with non-ST-segment elevation myocardial infarction and nonobstructive coronary artery disease: results from the can rapid risk stratification of unstable angina patients suppress adverse outcomes with early implementation of the ACC/AHA guidelines (CRUSADE) quality improvement initiative. Am Heart J. 2009;158:688-94.

6. Larsen AI, Galbraith PD, Ghali WA, Norris CM, Graham MM, Knudtson ML, et al. Characteristics and outcomes of patients with acute myocardial infarction and angiographically normal coronary arteries. Am J Cardiol. 2005;95:261-3.

7. Pasupathy S, Air T, Dreyer RP, Tavella R, Beltrame JF. Systematic review of patients presenting with suspected myocardial infarction and nonobstructive coronary arteries. Circulation. 2015;131:86170.

8. Johnston N, Jonelid B, Christersson C, Kero T, Renlund H, Schenck-Gustafsson K, et al. Effect of gender on patients with ST-elevation and non-ST-elevation myocardial infarction without obstructive coronary artery disease. Am J Cardiol. 2015;115:16616.

9. Najib K, Boateng S, Sangodkar S, Mahmood S, Whitney H, Wang $\mathrm{CE}$, et al. Incidence and characteristics of patients presenting with acute myocardial infarction and non-obstructive coronary artery disease. Catheter Cardiovasc Interv. 2015;86(Suppl 1):S23-7.

10. Safdar B, Spatz ES, Dreyer RP, Beltrame JF, Lichtman JH, Spertus JA, et al. Presentation, clinical profile, and prognosis of young patients with myocardial infarction with nonobstructive coronary arteries (MINOCA): results from the VIRGO study. J Am Heart Assoc. 2018;7.

11. Kochanek KD, Murphy SL, Xu J, Tejada-Vera B. Deaths: final data for 2014. Natl Vital Stat Rep. 2016;65:1-122.

12. Nordenskjold AM, Lagerqvist B, Baron T, Jernberg T, Hadziosmanovic N, Reynolds HR, et al. Reinfarction in patients with myocardial infarction with nonobstructive coronary arteries (MINOCA): coronary findings and prognosis. Am J Med. 2019;132:335-46.

13. Opolski MP, Spiewak M, Marczak M, Debski A, Knaapen P, Schumacher SP, et al. Mechanisms of myocardial infarction in patients with nonobstructive coronary artery disease: results from the optical coherence tomography study. JACC Cardiovasc Imaging. 2019;12:2210-21.

14. Jackson R, Al-Hussaini A, Joseph S, van Soest G, Wood A, Macaya F, et al. Spontaneous coronary artery dissection: pathophysiological insights from optical coherence tomography. JACC Cardiovasc Imaging. 2019;12:2475-88.

15. Patel MR, Chen AY, Peterson ED, Newby LK, Pollack CV Jr, Brindis RG, et al. Prevalence, predictors, and outcomes of patients with non-ST-segment elevation myocardial infarction and insignificant coronary artery disease: results from the Can Rapid risk stratification of Unstable angina patients Suppress ADverse outcomes with Early implementation of the ACC/AHA Guidelines (CRUSADE) initiative. Am Heart J. 2006;152:641-7.

16. Planer D, Mehran R, Ohman EM, White HD, Newman JD, Xu K, et al. Prognosis of patients with non-ST-segment-elevation myocardial infarction and nonobstructive coronary artery disease: propensity-matched analysis from the acute catheterization and urgent intervention triage strategy trial. Circ Cardiovasc Interv. 2014;7:285-93.

17. Dastidar AG, Baritussio A, De Garate E, Drobni Z, Biglino G, Singhal P, et al. Prognostic role of CMR and conventional risk factors in myocardial infarction with nonobstructed coronary arteries. JACC Cardiovasc Imaging. 2019 Oct;12(10):1973-82. https:// doi.org/10.1016/j.jcmg.2018.12.023.

18. Pasupathy S, Tavella R, Beltrame JF. Myocardial infarction with nonobstructive coronary arteries (MINOCA): the past, present, and future management. Circulation. 2017;135:1490-3.

19. Lintingre PF, Nivet H, Clément-Guinaudeau S, Camaioni C, Sridi $\mathrm{S}$, Corneloup O, et al. JACC High-resolution late gadolinium enhancement magnetic resonance for the diagnosis of myocardial infarction with nonobstructed coronary arteries. Cardiovasc Imaging. 2020.

20. Reynolds HR, Srichai MB, Iqbal SN, Slater JN, Mancini GB, Feit $\mathrm{F}$, et al. Mechanisms of myocardial infarction in women without angiographically obstructive coronary artery disease. Circulation. 2011;124:1414-25. 
21. Ouldzein H, Elbaz M, Roncalli J, Cagnac R, Carrie D, Puel J, et al. Plaque rupture and morphological characteristics of the culprit lesion in acute coronary syndromes without significant angiographic lesion: analysis by intravascular ultrasound. Ann Cardiol Angeiol (Paris). 2012;61:20-6.

22. Raber L, Mintz GS, Koskinas KC, Johnson TW, Holm NR, Onuma $\mathrm{Y}$, et al. Clinical use of intracoronary imaging. Part 1: guidance and optimization of coronary interventions. An expert consensus document of the European Association of Percutaneous Cardiovascular Interventions. EuroIntervention. 2018;14:656-77.

23. Zhang J, Gao X, Kan J, Ge Z, Han L, Lu S, et al. Intravascular ultrasound-guided versus angiography-guided implantation of drug-eluting stent in all-comers: the ULTIMATE trial. J Am Coll Cardiol. 2018;72:3126-37.

24. Prati F, Romagnoli E, Burzotta F, Limbruno U, Gatto L, La Manna A, et al. Clinical impact of OCT findings during PCI: the CLI-OPCI II study. JACC Cardiovasc Imaging. 2015;8:1297-305.

25. Terashima M, Kaneda H, Suzuki T. The role of optical coherence tomography in coronary intervention. Korean J Intern Med. 2012;27:1-12.

26. Huang D, Swanson EA, Lin CP, Schuman JS, Stinson WG, Chang W, et al. Optical coherence tomography. Science. 1991;254:117881.

27. Yabushita H, Bouma BE, Houser SL, Aretz HT, Jang IK, Schlendorf KH, et al. Characterization of human atherosclerosis by optical coherence tomography. Circulation. 2002;106:1640-5.

28. Kume T, Akasaka T, Kawamoto T, Okura H, Watanabe N, Toyota E, et al. Measurement of the thickness of the fibrous cap by optical coherence tomography. Am Heart J. 2006;152:755 e1-4.

29. Kubo T, Imanishi T, Takarada S, Kuroi A, Ueno S, Yamano T, et al. Assessment of culprit lesion morphology in acute myocardial infarction: ability of optical coherence tomography compared with intravascular ultrasound and coronary angioscopy. J Am Coll Cardiol. 2007;50:933-9.
30. Kume T, Akasaka T, Kawamoto T, Ogasawara Y, Watanabe N, Toyota E, et al. Assessment of coronary arterial thrombus by optical coherence tomography. Am J Cardiol. 2006;97:1713-7.

31. Kanda T, Tawarahara K, Matsukura G, Matsunari M, Takabayashi $\mathrm{R}$, Tamura J, et al. The diagnosis of spontaneous coronary artery dissection by optical coherence tomography. Intern Med. 2018;57: 523-6.

32. Chamie D, Bezerra HG, Attizzani GF, Yamamoto H, Kanaya T, Stefano GT, et al. Incidence, predictors, morphological characteristics, and clinical outcomes of stent edge dissections detected by optical coherence tomography. JACC Cardiovasc Interv. 2013;6: $800-13$.

33. Gonzalo N, Serruys PW, Okamura T, Shen ZJ, Onuma Y, GarciaGarcia HM, et al. Optical coherence tomography assessment of the acute effects of stent implantation on the vessel wall: a systematic quantitative approach. Heart. 2009;95:1913-9.

34. Kume T, Akasaka T, Kawamoto T, Watanabe N, Toyota E, Sukmawan R, et al. Visualization of neointima formation by optical coherence tomography. Int Heart J. 2005;46:1133-6.

35. Habara M, Terashima M, Nasu K, Kaneda H, Inoue K, Ito T, et al. Difference of tissue characteristics between early and very late restenosis lesions after bare-metal stent implantation: an optical coherence tomography study. Circ Cardiovasc Interv. 2011;4:232-8.

36. Johnson T, Räber L, di Mario C, Bourantas C, et al. Clinical use of intracoronary imaging. Part 2: acute coronary syndromes, ambiguous coronary angiography findings, and guiding interventional decision-making: an expert consensus document of the European Association of Percutaneous Cardiovascular Interventions: Endorsed by the Chinese Society of Cardiology, the Hong Kong Society of Transcatheter Endocardiovascular Therapeutics (HKSTENT) and the Cardiac Society of Australia and New Zealand. European Heart Journal. 2019;40(31):2566-84.

Publisher's Note Springer Nature remains neutral with regard to jurisdictional claims in published maps and institutional affiliations. 